\title{
RELATIONSHIP BETWEEN SEQUENTIAL ORGAN FAILURE ASSESSMENT (SOFA) AND INTRA-ABDOMINAL PRESSURE IN INTENSIVE CARE UNIT
}

Relação entre o Sequential Organ Failure Assessment (SOFA) e a pressão intra-abdominal em unidade de tratamento intensivo

Gustavo Rocha Costa de FREITAS, Olival Cirilo Lucena da FONSECA-NETO, Carla Larissa Fernandes PINHEIRO,

Luiz Clêiner ARAÚJO, Roberto Esmeraldo Nogueira BARBOSA, Pedro ALVES

Trabalho realizado no Serviço de Cirurgia Geral e do Trauma do Hospital da Restauração, Recife, PE, Brasil.
ABSTRACT - Background: Patients in the intensive care unit are at risk of developing intraabdominal hypertension and abdominal compartment syndrome. Aim: To describe the relation between Sequential Organ Failure Assessment (SOFA) vs. intra-abdominal pressure and the relation between SOFA and risk factors for intra-abdominal hypertension. Method: In accordance with the recommendations of the World Society of the Abdominal Compartment Syndrome, the present study measured the intra-abdominal pressure of patients $24 \mathrm{~h}$ and $48 \mathrm{~h}$ after admission to the unit and calculated the SOFA after $24 \mathrm{~h}$ and $48 \mathrm{~h}$. Data was collected over two-month period. Results: No correlation was found between SOFA and intraabdominal pressure. Seventy percent of the patients were men and the mean age was 44 years, $10 \%$ had been referred from general surgery (with a mean intra-abdominal pressure of 11 ) and $65 \%$ from neurosurgery (with a mean intra-abdominal of 6.7$)$. Only three $(7.5 \%)$ presented with intra-abdominal hypertension. The highest SOFA was 15 and the most frequent kind of organ failure was neurological, with a frequency of $77 \%$. There was a strong correlation between the SOFA after $24 \mathrm{~h}$ and $48 \mathrm{~h}$ and peak respiratory pressure $(\rho=0.43 / p=0.01 ; \rho=0.39 /$ $p=0.02$ ). Conclusion: No correlation was found between SOFA and intra-abdominal pressure in the patients covered by the present study. However, it is possible in patients undergoing abdominal surgery or those with abdominal sepsis. Não houve correlação entre o SOFA e a pressão intra-abdominal nos pacientes aqui estudados; contudo, sinalizou ser possível em pacientes com operação abdominal ou naqueles com sepse abdominal.
HEADINGS - Intra-abdominal hypertension. Multiple organ failure. Abdominal compartment syndrome. Intensive care unit. Cross-sectional studies.
RESUMO - Racional: Os pacientes em unidade de terapia intensiva estão em risco de desenvolver hipertensão intra-abdominal e síndrome compartimental abdominal. Objetivos: Descrever a relação entre o Sequential Organ Failure Assessment (SOFA) com a pressão intra-abdominal e a relação do SOFA com fatores de risco para hipertensão intra-abdominal. Método: Com base nas recomendações da World Society of Abdominal Compartment Syndrome, foram medidas as pressões intra-abdominais dos pacientes nas $24 \mathrm{~h}$ e $48 \mathrm{~h}$ da admissão na UTI e calculado o SOFA ao final das $24 \mathrm{~h}$ e $48 \mathrm{~h}$. O tempo de coleta foi de dois meses. Resultados: Não houve correlação entre o SOFA e a pressão intra-abdominal. Foram $70 \%$ de homens com idade média de 44 anos, sendo 10\% oriundos da cirurgia geral (pressão intra-abdominal média de 11) e $65 \%$ da neurocirurgia (pressão intra-abdominal média de 6,7). Apenas três $(7,5 \%)$ apresentaram hipertensão intra-abdominal. O SOFA máximo foi de 15 e a falência orgânica mais frequente foi a neurológica com $77 \%$. Houve forte correlação entre o SOFA das $24 \mathrm{~h}$ e $48 \mathrm{~h}$ com a pressão de pico respiratória $(\rho=0,43 / p=0,01 ; \rho=0,39 / p=0,02)$. Conclusões: Não houve correlação entre o SOFA e a pressão intra-abdominal nos pacientes aqui estudados; contudo, sinalizou ser possível em pacientes com operação abdominal ou naqueles com sepse abdominal.
DESCRTORES - Hipertensão IntraSíndrome compartimental abdominal. Unidade de terapia intensiva. Estudos transversais. and its physiopathology is still not fully understood. In most cases, it is the state of shock related to sepsis that leads to this dysfunction, but there are other cases where this does not appear. In these cases, it has been suggested that the intestine is the alternative "force ${ }^{\prime 1,2,3}$ driving the organ failure process. Recently, an experimental model has been developed that is capable of producing intra-abdominal hypertension associated with hypovolemia in rats. A subsequent anatomopathological study found signs of congestion and necrosis of intestinal villit.

The Sequential Organ Failure Assessment (SOFA) is the score that is currently most widely used in general ICUs. It assesses respiratory, hematological, liver, cardiovascular and neurological function. The key distinguishing feature of this score is that it follows the functioning of these organs on a daily basis and this is vital for diagnosis, treatment and controlling hospital costs. Other scores mark only a final figure without indicating which organs/systems are more or less compromised and are not as dynamic as the SOFA in assessing which segments are improving or deteriorating. This score makes it possible to perform a quick, simple and ongoing assessment of the separate functioning of various organs. A score of 3 or 4 for each function indicates organ failure and failure 
of 3 or more organs/systems has a mortality rate of over $70 \%$. The complexity of intestinal dysfunction and abdominal compartment as a whole is such that it cannot be included in the score either directly or indirectly ${ }^{1,5}$.

One way to assess the abdomen is to measure intra-abdominal pressure (IAP). The standard method recommended by the World Society of the Abdominal Compartment Syndrome is the vesical technique, using a Foley urinary catheter, with the mid-axillary line as zero level, infusion of no more than $25 \mathrm{ml}$ of water into the empty bladder, in a $0^{\circ}$ supine position, with measurements taken at the end of expiration when the patient is at rest in bed without abdominal contractions. A three-way tap needs to be connected to a $Y$ piece with a millimeter rule, a 16-calibre Jelco ${ }^{\circledR}$ and equipment for infusion of saline solution. The Jelco ${ }^{\circledR}$ is introduced into the connection between the bladder catheter and the collection bag under aseptic conditions, with the collection tube clamped near to the connection with the Foley catheter. When the meniscus of the saline solution settles in the millimeter rule, the measurement is taken, the mid-axillary line taken as the zero level $^{6}$. Originally described by Kron and colleagues, the technique established the zero level in the pubic symphysis and instilled between 50 and 100 $\mathrm{ml}$, which still generates divergences in daily practice ${ }^{7}$. More recent studies suggest that instilling $50-100 \mathrm{ml}$ overestimates the IAP and that volumes as low as $2 \mathrm{ml}$ are sufficient for measuring IAP, when using electronic monitoring devices ${ }^{8}$. The World Society of the Abdominal Compartment Syndrome defines intra-abdominal hypertension (IAH) as Grade I, if it lies between 12 and $15 \mathrm{mmHg}$; as Grade II, if it is $16-20 \mathrm{mmHg}$; Grade III, for 21-24 mmHg; and Grade IV for $>25 \mathrm{mmHg}$; and establishes an investigation and treatment protocol ${ }^{6}$. Another classification that is still used in some centers is that of Burchet et al. which defines IAH Grade I as between 10 and 15 $\mathrm{mmHg}$; Grade II, as $15-25 \mathrm{mmHg}$; Grade III, as $25-35 \mathrm{mmHg}$; and Grade IV as $>35 \mathrm{mmHg}^{9}$. The presence of $\mathrm{AIH}$ is variable and the figures range from 18 to $81 \%$, being influenced by the measurement method, the classification criteria and the profile of ICU patients. The predominant factors are clinical, surgical, neurocritical and polytraumatized ${ }^{10}$.

Despite being recommended worldwide as the routine measurement procedure, along with vital signs and water balance, the IAP is often used incorrectly in Brazilian ICUs, because of errors relating to the indication, execution, interpretation and use of the technique ${ }^{11}$. Critical patients are one of the groups that have more risk factors for developing $\mathrm{AIH}$ and its most serious complication, Abdominal Compartment Syndrome ${ }^{10,3}$. Pubmed contains no studies correlating the SOFA and IAP.

The present study therefore aimed to describe the relation between the SOFA and IAP in ICUs and the correlation between the SOFA and other clinical variables in patients in a critical condition.

METHODS

The study was registered at the Brazil Platform in accordance with the norms of Resolution 196/96 of the National Health Council and received no external funding.

A cross-sectional, observational study was carried out in a 28-bed ICU at the Hospital da Restauração in the city of Recife, in the Brazilian State of Pernambuco. Data were collected in August and September 2012. Around 25 patients are admitted to the ICU each month. The patients included in the sample were over 18 years in age and had been referred from various sectors of the hospital. The exclusion criteria were as follows: contraindication of bladder catheter by the ICU physician, kidney failure, peritoneostomy or death within 12 hours subsequent to admission to the ICU.

\section{Data collection}

A questionnaire was drawn up to collect demographic data and data relating to the SOFA criteria. The clinical and demographic data studied were age, sex, origin (post-anesthesia recovery room, wards, emergency), date of admission to hospital, date of admission to ICU and principal diagnosis. The laboratory data studied related to albumin, urea and creatinine. Also recorded were the volumes of crystalloids, colloids and hemoderivatives, the urinary deficiency and the water balance recorded on medical charts and the use of vasoactive drugs (noradrenalin/ dopamine). The vasoactive amines were considered for the SOFA, calculating the dose in $\mu \mathrm{g} / \mathrm{kg}$.min based on the highest rate of infusion registered during the $24 \mathrm{~h}$ period that lasted for at least $60 \mathrm{~min}$, in accordance with the SOFA protocol. To measure abdominal perfusion pressure - which is equivalent to mean arterial pressure minus intra-abdominal pressure - mean arterial pressure was also measured. The mechanical ventilation parameters recorded were positive expiratory end pressure (PEEP) and peak respiratory pressure.

The IAP of all eligible patients was measured every six hours for the first $48 \mathrm{~h}$ following admission to the ICU. It was measured using the technique recommended by the World Society of the Abdominal Compartment Syndrome, firstly in $\mathrm{cmH}_{2} \mathrm{O}$ and then converted into $\mathrm{mmHg}\left(1 \mathrm{mmHg}=1.36 \mathrm{cmH}_{2} \mathrm{O}\right)$ for inclusion in the database.

The SOFA was calculated $24 \mathrm{~h}$ and $48 \mathrm{~h}$ after admission, taking the lowest value attributed to the organ/function in the previous $24 \mathrm{~h}$. As described in the original SOFA study, the neurological system is the most complex parameter to measure, owing to the frequent use of sedatives in ICUs. Vincent and colleagues have thus suggested that real and/or presumed Glasgow coma scores by considered and continually reevaluated, as this is a dynamic process. The present study a score of 6-9 on this score, equivalent to 3 on the SOFA, was considered for all intubated patients.

\section{Statistical Analysis}

The sample size was based on the mean incidence of $50 \%$ reported in the literature for any degree of $\mathrm{AIH}$ in general ICU patients, giving a total of 40 patients ${ }^{3}$. The results were analyzed using percentages, mean as a measure of central tendency and the range or quartiles as a measure of spread for the quantitative variables, the Kolmogorov-Smirnov test for normality, Fisher's exact test to measure the statistical significance of associations between categorical variables and Pearson's correlation to quantify these associations ( $\alpha=5 \%$ ). All information not found was considered to be unknown. The statistical analysis software used was SPSS (Statistical Package for the Social Sciences, Windows Version 17.0, Chicago, IL).

\section{RESULTS}

Fifty-five patients were admitted during the period and 15 were excluded, four who were under 18 years of age, four who did not need a bladder catheter, three who were on dialysis, one with peritoneostomy and three who died less than $12 \mathrm{~h}$ after admission. Most of the individuals included in the sample were male (70\%) and the mean age was 44.42 years; $82.5 \%$ had been admitted following surgery, $65 \%$ neurosurgery and $10 \%$ general surgery. Only $7.5 \%$ had developed severe sepsis (Table 1 ).

The mean IAP and SOFA $24 \mathrm{~h}$ and $48 \mathrm{~h}$ after admission are given in Table 2, along with the mean arterial pressure and the abdominal perfusion pressure (APP). Figure 1 show the distribution of IAP means $24 \mathrm{~h}$ and $48 \mathrm{~h}$ after admission to ICU and the normal curve. The lowest mean arterial pressure and abdominal perfusion pressure found were 55.5 and $43.0 \mathrm{mmHg}$, respectively. Patients coming from general surgery had a mean IAP of 11.0, compared with 6.7 for those coming 
from neurosurgery. Only three had IAH and it was possible to calculate the SOFA for only one, who presented with three failed systems: coagulation, cardiovascular and neurological (Table 3). The most frequent system failures were neurological (77\% after $48 \mathrm{~h}$ ), respiratory ( $45 \%$ after $48 \mathrm{~h}$ ) and cardiovascular ( $22.5 \%$ after $24 \mathrm{~h}$ ); $20 \%$ of patients scored the maximum for cardiovascular function in the first $24 \mathrm{~h}$, because of the use of high doses of vasoactive drugs. No colloids were used.

The association between SOFA and sex, age and IAP was examined using Fisher's exact test. There was no statistically significant association between SOFA and IAP after $24 \mathrm{~h}$ and 48 h ( $24 \mathrm{~h} \mathrm{p}=0.50 ; 48 \mathrm{~h} \mathrm{p}=0.29$ ). The only significant association was between SOFA after $48 \mathrm{~h}$ and sex $(p<0.05)$ (Table 4).

TABLE 1 - General clinical findings

\begin{tabular}{|c|c|c|}
\hline \multirow{2}{*}{$\operatorname{Sex}(n, \%)$} & Male & $28(70 \%)$ \\
\hline & Female & $12(30 \%)$ \\
\hline \multirow{2}{*}{ Age } & Min-Max & $18-78$ \\
\hline & Mean & 44.42 \\
\hline \multirow{3}{*}{$\begin{array}{l}\text { Origin } \\
(n, \%)\end{array}$} & Post-anesthesia recovery room & $33(82.5 \%)$ \\
\hline & Wards & $4(10 \%)$ \\
\hline & Emergency surgery & $3(7.5 \%)$ \\
\hline \multirow{3}{*}{$\begin{array}{l}\text { Days up to } \\
\text { admission to ICU }\end{array}$} & 25th percentile & 1 \\
\hline & 50th percentile & 3 \\
\hline & 75th percentile & 6.75 \\
\hline \multirow{5}{*}{$\begin{array}{l}\text { Reason for } \\
\text { admission }\end{array}$} & Following neurosurgery & $26(65 \%)$ \\
\hline & Following general surgery & $4(10 \%)$ \\
\hline & Severe sepsis & $3(7.5 \%)$ \\
\hline & Multiple trauma & $4(10 \%)$ \\
\hline & Other & $3(7.5 \%)$ \\
\hline
\end{tabular}

TABLE 2 - Ranges, means and quartiles after $24 \mathrm{~h}$ and 48 $\mathrm{h}$ for IAP, mean arterial pressure, abdominal perfusion pressure and SOFA

\begin{tabular}{cccccccccc} 
& & $\mathrm{N}$ & Min & Max & Mean & \multicolumn{3}{c}{ Quartile } \\
\hline IAP & $24 \mathrm{~h}$ & 40 & 2.5 & 12.6 & 7.15 & 5.1 & 6.3 & 9.5 \\
$(\mathrm{mmHg})$ & $48 \mathrm{~h}$ & 39 & 2.9 & 15.7 & 7.39 & 5.5 & 6.9 & 8.4 \\
\hline $\begin{array}{c}\text { MAP } \\
(\mathrm{mmHg})\end{array}$ & $24 \mathrm{~h}$ & 40 & 55.5 & 129.5 & 96.4 & 85.9 & 94.0 & 109.0 \\
\hline APP & $24 \mathrm{~h}$ & 40 & 43.0 & 119.8 & 89.2 & 80.3 & 87.6 & 103.1 \\
$(\mathrm{mmHg})$ & $48 \mathrm{~h}$ & 39 & 58.9 & 144.9 & 92.5 & 80.5 & 89.7 & 101.2 \\
\hline SOFA & $24 \mathrm{~h}$ & 33 & 5 & 14 & 10.75 & 9.5 & 11 & 12.5 \\
& $48 \mathrm{~h}$ & 33 & 7 & 15 & 10.78 & 10 & 10 & 12
\end{tabular}

$\mathrm{IAP}=$ intra-abdominal pressure; $\mathrm{MAP}=$ mean arterial pressure; $\mathrm{APP}=$ abdominal perfusion pressure
TABLE 3- Characteristics of patients with intra-abdominal hypertension

\begin{tabular}{|c|c|c|c|c|c|}
\hline Sex & Age & Origin & Reason & $\begin{array}{l}\text { Mean IAP } \\
24-48 \mathrm{~h}\end{array}$ & $\begin{array}{c}\text { SOFA 24- } \\
48 \mathrm{~h}\end{array}$ \\
\hline M & 50 & RR - NS & Severe head trauma & $12.6-14.5$ & * \\
\hline $\mathrm{F}$ & 72 & $\mathrm{RR}-\mathrm{CV}$ & $\begin{array}{l}\text { Ruptured aneurysm } \\
\text { in abdominal aorta }\end{array}$ & $12.4-15.7$ & * \\
\hline $\mathrm{F}$ & 44 & $R R-G S$ & $\begin{array}{l}\text { Closed abdominal } \\
\text { trauma and } \\
\text { mesenteric ischemia }\end{array}$ & $9.1-14.0$ & $14-13$ \\
\hline
\end{tabular}

*Insufficient data for calculation of SOFA; IAPin $\mathrm{mmHg}=$ intra-abdominal pressure; $\mathrm{RR}=$ recovery room; $N S=$ neurosurgery; $\mathrm{CV}=$ vascular surgery; $\mathrm{GS}=$ general surgery


FIGURE 1 - Distribution of mean intra-abdominal pressure 24 $\mathrm{h}$ and $48 \mathrm{~h}$ after admission to ICU and normal curve

TABLE 4 - Number and percentage of patients by SOFA and level of statistical significance of correlation with sex, age and intra-abdominal pressure

\begin{tabular}{|c|c|c|c|c|c|}
\hline & & & FA Score 2 & & \\
\hline & & $<12$ n (\%) & $>12$ n (\%) & $\begin{array}{c}\text { Total } n \\
(\%)\end{array}$ & $p$ \\
\hline & $M$ & $18(72)$ & $7(28)$ & $25(100)$ & \\
\hline Sex & $\mathrm{F}$ & $3(37,5)$ & $5(62,5)$ & $8(100)$ & 0,10 \\
\hline Total & & $21(63,6)$ & $12(36,4)$ & $33(100)$ & \\
\hline & $18-40$ & $9(60)$ & $6(40)$ & $15(100)$ & \\
\hline Age & $41-60$ & $5(50)$ & $5(50)$ & 10 (100) & 0,49 \\
\hline & $>60$ & $5(83,4)$ & $1(16,6)$ & $6(100)$ & \\
\hline Total & & $19(61,3)$ & $12(38,7)$ & $31(100)$ & \\
\hline & $<10$ & $17(65,4)$ & $9(34,6)$ & $26(100)$ & \\
\hline IAP $24 \mathrm{~h}$ & $\geq 10$ & $4(57,1)$ & $3(42,9)$ & 7 (100) & 0,50 * \\
\hline Total & & $21(63,6)$ & $12(36,4)$ & $33(100)$ & \\
\hline & $<10$ & $2(40)$ & & & \\
\hline IAP 48 & $\geq 10$ & $3(60)$ & & & NA \\
\hline Total & & $5(100)$ & & & \\
\hline
\end{tabular}

\begin{tabular}{|c|c|c|c|}
\hline \multicolumn{4}{|c|}{ SOFA Score $48 \mathrm{~h}$} \\
\hline$<12 \mathrm{n}(\%)$ & $>12 \mathrm{n}(\%)$ & Total $\mathrm{n}(\%)$ & $\mathrm{p}$ \\
\hline $20(80)$ & $5(20)$ & $25(100)$ & \\
\hline $3(37,5)$ & $5(62,5)$ & $8(100)$ & 0,03 \\
\hline $23(69,7)$ & $10(30,3)$ & $33(100)$ & \\
\hline $9(60)$ & $6(40)$ & $15(100)$ & \\
\hline $7(70)$ & $3(30)$ & $10(100)$ & 0,69 \\
\hline $5(83,4)$ & $1(16,6)$ & $6(100)$ & \\
\hline $21(67,7)$ & $10(32,3)$ & $31(100)$ & \\
\hline & & & NA \\
\hline $20(74)$ & $7(26)$ & $27(100)$ & \\
\hline $2(40)$ & $3(60)$ & $5(100)$ & 0,29 \\
\hline $2(68,8)$ & $10(31,2)$ & $32(100)$ & \\
\hline
\end{tabular}

Two-tailed Fisher's exact test; $\mathrm{NA}=$ not applicable; *One-tailed Fisher test IAP= intra-abdominal pressure 
Pearson's test was applied to the SOFA after $24 \mathrm{~h}$ and $48 \mathrm{~h}$ and the other variables studied. There was a strong statistically significant positive correlation between the SOFA after $24 \mathrm{~h}$ and the volume of crystalloids $(\rho=0.58 ; p<0.01)$. There was a strong negative correlation between the SOFA after $48 \mathrm{~h}$ and albumin levels $(\rho=-0.52 ; p=0.01)$. Only peak respiratory pressure was positively associated with the SOFA after both $24 \mathrm{~h}$ and 48 h $(\rho=0.93 p=0.02 ; \rho=0.43 p=0.01)$. There was no statistically significant correlation with the other variables, including IAP after $24 \mathrm{~h}$ and $48 \mathrm{~h}$ (Table 5).

TABLE 5 - Analysis of correlation between the SOFA after 24 $\mathrm{h}$ and $48 \mathrm{~h}$ and clinical, laboratory and ventilator variables by Pearson's coefficient $(\rho)$

\begin{tabular}{|c|c|c|c|c|c|c|}
\hline & \multicolumn{3}{|c|}{ SOFA $24 \mathrm{~h}$} & \multicolumn{3}{|c|}{ SOFA $48 \mathrm{~h}$} \\
\hline & $\mathbf{n}$ & $\rho$ (Pearson) & $p$ & $\mathrm{~N}$ & $\rho$ (Pearson) & P \\
\hline \multicolumn{7}{|c|}{ Clinical and laboratory variables } \\
\hline Age & 31 & 0.049 & 0.793 & 31 & -0.083 & 0.658 \\
\hline Urea & 21 & -0.072 & 0.757 & 33 & 0.211 & 0.239 \\
\hline Creatinine & 21 & 0.115 & 0.619 & 33 & 0.178 & 0.321 \\
\hline Albumin & 7 & -0.001 & 0.998 & 20 & -0.527 & 0.017 \\
\hline $\begin{array}{c}\text { Urinary } \\
\text { deficiency }\end{array}$ & 30 & ח 10 & 0.943 & 29 & 0.208 & 80 \\
\hline Water balance & 30 & 0.314 & 0.091 & 29 & -0.096 & 0.620 \\
\hline $\begin{array}{l}\text { Volume of } \\
\text { crystalloids }\end{array}$ & 20 & 0.589 & 0.006 & 33 & 0.185 & 0.303 \\
\hline \multicolumn{7}{|l|}{ Pressure variables } \\
\hline IAP & 33 & 0.201 & 0.261 & 32 & 0.258 & 0.154 \\
\hline MAP & 33 & -0.219 & 0.221 & 32 & -0.215 & 0.236 \\
\hline APP & 33 & -0.262 & 0.140 & 32 & -0.262 & 0.147 \\
\hline \multicolumn{7}{|c|}{ Mechanical Ventilation variables } \\
\hline PEEP & 32 & -0.105 & 0.568 & 32 & 0.229 & 0.207 \\
\hline Ppeak & 33 & 0.430 & 0.013 & 32 & 0.394 & 0.026 \\
\hline
\end{tabular}

$\mathrm{P}=\mathrm{p}$-value; $\mathrm{IAP}=$ intra-abdominal pressure; $\mathrm{MAP}=$ mean arterial pressure; $A P P=$ abdominal perfusion pressure; $P E E P=$ positive expiratory end pressure;Ppeak=peak pressure

\section{DISCUSSION}

The evaluation of the abdomen is a challenge in ICUs. The SOFA is the most widely accepted mortality score in the world, although it does not evaluate the abdomen and this short coming was acknowledged by Vincent and colleagues in their original study of the SOFA. Nevertheless, little has been done to find a parameter for evaluating the abdomen. As of November 2012, there were no articles in the Pubmed database on this subject.

The individuals in the study sample had various risk factors for IAP, such as abdominal surgery, mechanical ventilation, vasoactive drug use, multiple trauma, gastroparesis, liver failure, acidosis, coagulopathy and sepsis. Despite this, the prevalence of intra-abdominal hypertension was $7.5 \%$ according to the criteria of the World Society of the Abdominal Compartment Syndrome. Using the classification developed by Bursh et al. the prevalence is expected to be $20 \%$ in the first $24 \mathrm{~h}$ and $15 \%$ up to $48 \mathrm{~h}$. The SOFA, in turn, was higher, beginning at 9.5 in the first quartile indicating a significant number of organ dysfunctions among patients in this sample.

One Brazilian study assessed IAH after surgery for open or closed abdominal trauma in 20 patients and found a mean IAP of $10.4 \mathrm{cmH} 2 \mathrm{O}(7.6 \mathrm{mmHg})$ in the first $6 \mathrm{~h}$ and $10.2 \mathrm{cmH} 2 \mathrm{O}$ $(7,5 \mathrm{mmHg}) 18 \mathrm{~h}$ after surgery. A positive correlation was found between the volume of colloids infused and the IAP, according to Pearson's test ${ }^{12}$. It is not possible to compare these results with those of the present study, owing to the different techniques used. The present study followed the recommendations of the World Society of the Abdominal Compartment Syndrome, while the previous one used Kron's original technique?.

In the present study, there was no significant correlation either in the sample overall or in any subgroup between the SOFA and IAP. The only significant correlations were between the SOFA and the volume of crystalloids, peak respiratory pressure and albumin, although a number of remarks should be made regarding these.

The volume of crystalloids infused in the $24 \mathrm{~h}$ prior to the SOFA was strongly correlated with the SOFA after $24 \mathrm{~h}$, which would seem to indicate that the greater the volume infused the higher the SOFA score. It should be noted, however, that, in the first $24 \mathrm{~h}$, only 20 patients had valid records of volume de crystalloids $(p<0.01)$. In the following $48 \mathrm{~h}$ records were obtained for 33 patients and the $p$-value was no longer significant. Despite the existence of a physiopathological substrate for this association, this finding may have been due to the small sample size during the first $24 \mathrm{~h}$.

Albumin levels showed a strong negative correlation with the SOFA after $48 \mathrm{~h}$, indicating that the lower the patient's albumin, the worse the SOFA score. This was not the case with the SOFA after $24 \mathrm{~h}$, perhaps because of the number of patients who under went this examination $(7=17,5 \%)$. Albumin levels did not vary significantly in the first $24 \mathrm{~h}$. Therefore, despite the fact that the $\mathrm{p}$-value was $<0.05$ in the first $24 \mathrm{~h}$, the finding for $48 \mathrm{~h}$ is more important.

The peak respiratory pressure was the only variable that was significant after both $24 \mathrm{~h}$ and $48 \mathrm{~h} .82 .5 \%$ of patients had valid records after $24 \mathrm{~h}$ and $80 \%$ after $48 \mathrm{~h}$. The physiopathological substrate for this correlation is that positive intra-thoracic positive pressure resulting from mechanical ventilation is also transmitted to the abdomen and may contribute to heightening IAP, as an addition, but not the only factor. The reverse is also true.

When viewed in isolation, these variables may suggest that the patient is more compromised, since homeostasis requires more volume, higher pressure, higher peak respiratory pressure and the albumin level indicates catabolism. However, none of these factors contribute to the SOFA score, while all are risk factors for IAH. Although no correlation between SOFA and IAP was found, there is a physiopathological substrate that justifies fuller investigation of these parameters.

This study had a number of limitations. It was carried out over a short period at a single center in an ICU that primarily serves patients who have undergone neurosurgery, who do not have a high risk of developing $\mathrm{AIH}$, compared to patients with abdominal sepsis or who have undergone abdominal surgery.

\section{CONCLUSION}

No correlation was found between the SOFA and intraabdominal pressure in the patients studied here. However, there may be such a correlation in patients who have undergone abdominal surgery or who have abdominal sepsis.

REFERENCES

1. Burch J. The abdominal compartiment syndrome. Surgery Clinical North American. 1996: p. 833-842.

2. Cecchi A, Anichini $V$, Batachi S. Intra-abdominal pressure and Sequential Organ Failure Assessment score: is there a correlation? Critical Care. 2006 March: p. P310.

3. De Laet I, Hoste E, De Wahele J. Ultralow volumes in transvesical intra-abdominal pressure measurement. Critical Care Medicine. 2006: p. P307.

4. De Waele J, De Laet I, Kirkpatrick A, Hoste E. Intra-abdominal hypertension and Abdominal Compartment Syndrome. American Journal of Kidney Disease. 2010 August: p. 159-169.

5. Japiassú A, FalcãoH, FreitasF, FreitasS, SouzaP, Lannes R. Mensuração da Pressão Intra-Abdominal nas Unidades de Tratamento Intensivo. A opnião dos médicos intensivistas. Revista Brasileira de Terapia Intensiva. 2007 Março: p. 186-191.

6. Kirkpatrick Aw, Roberts $D_{j}$, De Waele J, Jaeschke R, et al. Intraabdominal hypertension and abdominal comportament syndrome: Updated consensus definitions and clinical practice guidelines from the world society of the abdominal comportment syndrome. Intensive care Med 2013 Jul; 39(7): 1190-206. DOI: 10.1007/s 00134013-2906-z. 
7. Kron IL, Harman PK, Nolan SP. The measurement of intra-abdominal pressure as a criterion for abdominal re-exploration. Annals of Surgery. 1984 June: p. 28-30.

8. LFA $P, A$ AJ, ES C, RS A. Pressão Intra-abdominal em pacientes com trauma Intra-abdominal. Revista do Colégio Brasileiro de Cirurgiões. 2005 Jan: p. 83-89.

9. Lima R, Schanaider A, Santana M, Oliveira M, Capelozzi V, Rocco P. Desenvolvimento de um novo modelo experimental de síndrome do compartimento abdominal. Revista do Colégio Brasileiro de Cirurgiões [periódico na Internet]. 2011: p. 417-421.

10. Malbrain ML, Cheatham ML, Kirkpatrick A, Sugrue M, Parr M. Results from the International Conference of Experts on Intra-abdominal Hypertension and Abdominal Compartment Syndrome. Intensive Care Medicine. 2006 November: p. 1722-1732.

11. Malbrain $M$, Chiumelo $D$, Pelosi $P$, Bichari $D$, Innes R. Incidence and prognosis of intraabdominal hypertension in a mixed population of critically ill patients: A multiple center epidemiological study. Critical Care Medicine. 2005: p. 315-322.
12. Marshall JC, Vincent JL, Fink MP. Measures, markers, and mediators: toward a staging system for clinical sepsis.. Critical Care Medicine. 2003 October: p. 1560-1567.

13. Vincent JL, De Mendonça A, Cantraine A, Moreno R, Takala J, Sutter $P$, et al. Use of the SOFA score to assess the incidence of organ dysfunction/failure in intensive care units: Results of a multicenter prospective study. Critical Care Medicine. 1998 November: p. 1793800.

14. Vincent JL, Moreno R, Takala J, Willatts S, De Mendonça A, Bruining $\mathrm{H}$, et al. The SOFA (Sepsis-Related Organ Failure Assessment) score to describe organ dysfunction/failure. Intensive Care Medicine. 1996 July: p. 707-710. 